\title{
Toxoplasmosis complicating lung cancer: a case report
}

This article was published in the following Dove Press journal:

International Medical Case Reports Journal

22 January 2015

Number of times this article has been viewed

\section{Nianhong Lu \\ Caihong Liu \\ Jiangyuan Wang \\ Ying Ding \\ Qing $A i$}

Department of Clinical Laboratory, The First Hospital of Jilin University, Changchun, People's Republic of China
Correspondence: Qing Ai

Department of Clinical Laboratory, The First Hospital of jilin University, 3302 jilin Road, Changchun, Jilin, | 3003 I, People's Republic of China

Tel +86 I37 5666 I670

Fax +86 043। 84808288

Email aiqing@jlu.edu.cn
Abstract: Toxoplasmosis complicating lung cancer has been described only rarely. Here, we report a case of acute Toxoplasma gondii infection in a patient with squamous lung cancer. A 64-year-old woman was admitted to our hospital with a history of cough of 6 months' duration and chest pain of 1 week's duration. Further examination revealed multiple swollen lymph nodes, palpable on the top of the right collarbone and without tenderness. The chest $\mathrm{X}$-ray, bronchoscopy, and computed tomography scan confirmed squamous carcinoma of the right lung. The Wright-stained bronchoalveolar-lavage fluid cytology diagnosis was positive for $T$. gondii and tachyzoites were detected. All of them were of free type (ectocytic), without intracellular parasites. Serological examination revealed that the anti-T. gondii immunoglobulin (Ig) $\mathrm{M}$ and $\mathrm{IgG}$ antibodies were positive. Unfortunately the patient did not continue treatment and was lost to follow-up. Toxoplasmosis is a life-threatening opportunistic infection in patients with lung cancer. Prompt recognition of $T$. gondii infection among cancer patients with subsequent targeted treatment of toxoplasmosis could help alleviate symptoms and improve survival.

Keywords: lung cancer, Toxoplasma gondii, bronchoalveolar-lavage fluid, tachyzoite

\section{Introduction}

Toxoplasma gondii infection, "toxoplasmosis", is relatively common, and the prevalence of carrying the dormant, cystic form has been reported as $40 \%$ in Europe, $20 \%-50 \%$ in Africa, ${ }^{1}$ and $10 \%-30 \%$ in the People's Republic of China. ${ }^{1,2}$ Most people who carry T. gondii are healthy, but for those with HIV or cancer toxoplasmosis can be lifethreatening. Toxoplasmosis has been reported to increase the fatality rate of Hodgkin's disease, leukemia, myeloma, melanoma, AIDS, and brain cancer. ${ }^{2-12}$ Although toxoplasmosis is known to complicate pneumonia and other respiratory diseases, ${ }^{12-20}$ its role in lung cancer has not been adequately described. Here, we describe a case of toxoplasmosis presenting with non-small-cell lung cancer for the purpose of making screening and treatment recommendations.

\section{Case presentation}

A 64-year-old Chinese woman was admitted to our hospital with a history of nonproductive cough (without hemoptysis) of 6 months' duration and chest pain of 1 week's duration. She had lived in a rural area with a cat for many years. She had no history of eating raw or undercooked foods and she was uncertain whether she had ever drunk unpasteurized goat's milk. Her medical history was unremarkable. She did not have shortness of breath, fever or sweats, weight loss, or a history of smoking. 
Physical examination revealed multiple swollen lymph nodes palpable on the top of the right collarbone, without tenderness. Temperature, respiration, heart rate, and abdominal examination showed no abnormalities. Other systemic examinations were within normal limits.

The chest radiograph showed bilateral prominence and right hila adenopathy. Computed tomography scan of the lung showed space-occupying lesions in the lower right lobe confirming centrally located carcinoma. We also observed significant enlargement of the lymph nodes in the right hilar areas and mediastinum, which we considered malignant. The patient also had pneumonia in the right lung. Bronchoscopy suggested that tracheal carina was broadened; the ridge between upper right lobe and middle bronchus was widened, as was the ridge between middle right lobe and lower lobe bronchus. Bronchoscopy also showed the right posterior basal bronchus suffered from compressed bronchostenosis. Squamous carcinoma cells were found in the bronchial brushing. There was no evidence of distant metastasis. Echocardiography suggested pulmonary hypertension. Pulmonary ventilation and small-airway function were mildly blocked.

Laboratory testing demonstrated no obvious abnormality except the carcinoembryonic antigen level was at $8.21 \mathrm{ng} / \mathrm{mL}$ (reference interval: $0-5 \mathrm{ng} / \mathrm{mL}$ ). Exfoliative cytology examination of the hydrothorax did not detect tumor cells. Interestingly, the Wright-stained bronchoalveolarlavage (BAL) fluid cytology diagnosis was positive for T. gondii (Figure 1), and many crescent-shaped tachyzoites

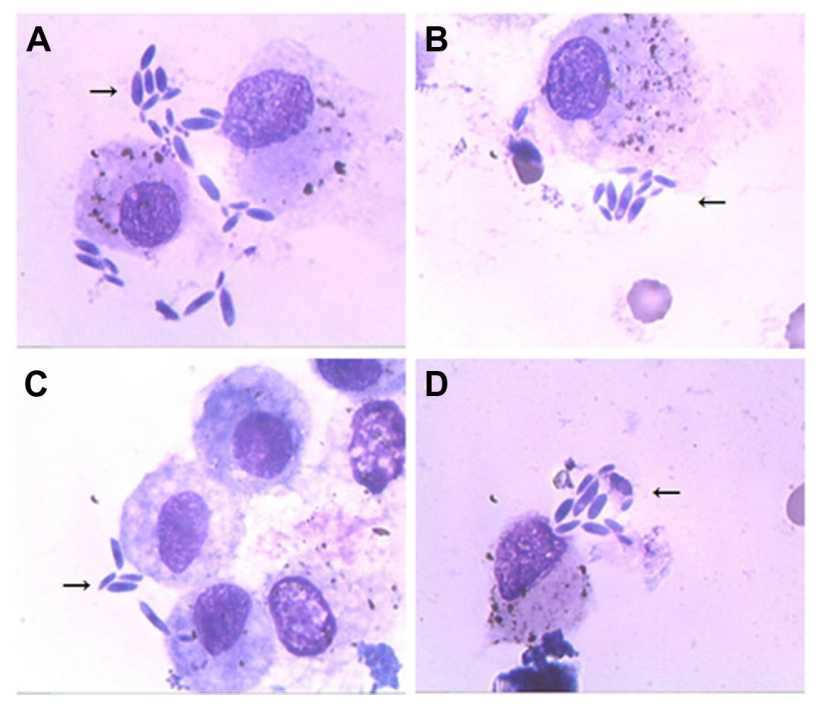

Figure I Wright-stained bronchoalveolar lavage fluid smears.

Notes: (A-D) Arrows indicate extracellular "tachyzoites", also known as "trophozoites", which can be propagated within the nucleated cells. No intracellular parasites are present. Magnification $\times 1,000$. were detected in clumps around host cells (indicated by an arrow in each of Figure 1A-D). Individual elongated bodies averaged 4-7 $\mu \mathrm{m}$ in length, with a pointed anterior end and rounded posterior end; one side was slightly flattened, the other side bulged. The nucleus was situated toward the center. All of the tachyzoites were extracellular (ectocytic); no intracellular parasite was evident. Serological examination revealed that anti- $T$. gondii immunoglobulin ( $\mathrm{Ig}) \mathrm{M}$ and $\mathrm{IgG}$ antibodies were positive. Other lab tests were unremarkable. The leukocyte count was $5.64 \times 10^{9} / \mathrm{L}$ (41.8\% lymphocytes, $52.1 \%$ neutrophils, $5.3 \%$ monocytes), and liver function tests were within the normal ranges (albumin $42.8 \mathrm{~g} / \mathrm{L}$, total bilirubin $10.10 \mu \mathrm{mol} / \mathrm{L}$, direct bilirubin $2.5 \mu \mathrm{mol} / \mathrm{L}$, alanine aminotransferase [ALT] $7.0 \mathrm{IU} / \mathrm{L}$, aspartate transaminase [AST] 17.0 IU/L). Serology testing for HIV was negative.

Upon diagnosis of lung cancer, the patient decided to forgo any kind of treatment and we subsequently lost contact with her.

\section{Discussion}

T. gondii is an obligate intracellular protozoan. ${ }^{15}$ The lifecycle of $T$. gondii is divided into five stages: trophozoite, cyst, schizont, gametophyte, and oocyst. Final maturation to sexual maturity occurs only in the intestines of cats. The main route of infection of $T$. gondii is fecal-oral transmission. It also can be transmitted to the fetus through the placenta. Generally, eosinophilia is not typical when infected with the protozoan. Clinical manifestations are complicated and atypical, and most infections are latent or acute. Differential diagnosis relies mainly on direct detection of Toxoplasma tachyzoites in BAL or by serological techniques.

Among healthy people, toxoplasmosis is generally mild and self-limiting, but among neonates and cancer patients, this opportunistic infection is serious, often fatal. Many cases of pulmonary toxoplasmosis have been described in patients with hematologic malignancies and solid tumors, but none in lung cancer, as far as we are aware.

We discovered a rare case of $T$. gondii infection in a lung cancer patient, with diagnosis of infection based on tachyzoites present in BAL and positive $T$. gondiispecific IgM antibody, and diagnosis of squamous lung cancer based on chest X-ray, bronchoscopy, and computed tomography scan.

Other investigators have described pulmonary toxoplasmosis in those with HIV or cancer, ${ }^{13-20}$ although not in lung cancer. A French nationwide study reviewed 64 cases of BAL-confirmed pulmonary toxoplasmosis among patients with HIV infection; 30 (47\%) of the 64 cases were responsive 
to toxoplasmosis treatment, while 24 patients (37\%) died of toxoplasmosis. Israelsky and Remington, in the USA, have also reported improved outcomes resulting from treatment of T. gondii infection among immune compromised patients. ${ }^{5}$ They reported improvement in $68 \%$ of patients for whom the diagnosis was made early enough to begin treatment. ${ }^{5}$ De Salvador-Guillouët et al reported a case of severe acute primary pulmonary toxoplasmosis in an immunocompetent of 19-year-old French man with BAL-confirmed tachyzoites. ${ }^{14}$ Leal et al reported a similar case in Brazil. ${ }^{19}$ In their paper, Leal et al also reviewed nine other cases of T. gondii pneumonia. Most of these cases had positive IgM and IgG T. gondii-specific antibodies and tachyzoite in BAL fluid. Fortunately most of these patients responded to treatment and made a full recovery.

Clinicians should be aware of toxoplasmosis complicating lung cancer, as toxoplasmosis is readily treatable. Indeed, in some countries $T$. gondii serology is ordered routinely during examination of cancer patients, with BAL fluid being the material of choice for diagnosing pulmonary toxoplasmosis as well as lung biopsies. ${ }^{16-18}$

We report a case of toxoplasmosis complicating squamous cell lung cancer in the People's Republic of China. We recommend consideration of periodic monitoring of $T$. gondii infection in lung cancer patients in order to improve treatment and increase survival.

\section{Acknowledgments}

We would like to thank Dr Lisa Herrinton (Division of Research, Kaiser Permanente, Oakland, CA, USA) and Dr Changyu Zheng (National Institute of Dental and Craniofacial Research, National Institute of Health, Bethesda, MD, USA) for editing this manuscript. This study was funded by the Technology Development Program of Jilin Province (no 200705178).

\section{Disclosure}

The authors report no conflict of interest in this work.

\section{References}

1. Furtado JM, Smith JR, Belfort R Jr, Gattey D, Winthrop KL. Toxoplasmosis: a global threat. J Glob Infect Dis. 2011;3(3):281-284.

2. Zhou P, Chen Z, Li HL, et al. Toxoplasma gondii infection in humans in China. Parasit Vectors. 2011;4:165.
3. Carey RM, Kimball AC, Armstrong D, Lieberman PH. Toxoplasmosis. Clinical experiences in a cancer hospital. Am J Med. 1973;54(1): 30-38.

4. Darcy F, Santoro F. Toxoplasmosis. In: F Kierszenbaum, editor. Parasitic Infections and the Immune System. New York, NY: Academic Press;1994:163-201.

5. Israelsky DM, Remington JS. Toxoplasmosis in patients with cancer. Clin Infect Dis. 1993;17 Suppl 2:S423-S435.

6. Edvinsson B, Lappalainen M, Anttila VJ, Paetau A, Evengård B. Toxoplasmosis in immunocompromized patients. Scand J Infect Dis. 2009;41(5):368-371.

7. Scerra S, Coignard-Biehler H, Lanternier F, et al. Disseminated toxoplasmosis in non-allografted patients with hematologic malignancies: report of two cases and literature review. Eur J Clin Microbiol Infect Dis. 2013;32(10):1259-1268.

8. Vietzke WM, Zelderman AH, Grimley PH, Welsmis MP. Toxoplasmosis complicating malignancy. Experience at the National Cancer Institute. Cancer. 1968;21(5):816-827.

9. Lazenby GB. Opportunistic infections in women with HIV AIDS. Clin Obstet Gynecol. 2012;55(4):927-937.

10. Benito N, Moreno A, Miro JM, Torres A. Pulmonary infections in HIV-infected patients: an update in the 21st century. Eur Respir $J$. 2012;39(3):730-745.

11. Pupaibool J, Limper AH. Other HIV-associated pneumonias. Clin Chest Med. 2013;34(2):243-254.

12. Tokman S, Huang L. Evaluation of respiratory disease. Clin Chest Med. 2013;34(2):191-204.

13. Rabaud C, May T, Lucet JC, Leport C, Ambroise-Thomas P, Canton P. Pulmonary toxoplasmosis in patients infected with human immunodeficiency virus: a French National Survey. Clin Infect Dis. 1996;23(6): 1249-1254.

14. De Salvador-Guillouët F, Ajzenberg D, Chaillou-Opitz S, et al. Severe pneumonia during primary infection with an atypical strain of Toxoplasma gondii in an immunocompetent young man. $J$ Infect. 2006;53(2):e47-e50.

15. Black MW, Boothroyd JC. Lytic cycle of Toxoplasma gondii. Microbiol Mol Biol Rev. 2000;64(3):607-623.

16. Pomeroy C, Filice GA. Pulmonary toxoplasmosis: a review. Clin Infect Dis. 1992;14(4):863-870.

17. Sing A, Leitritz L, Roggenkamp A, et al. Pulmonary toxoplasmosis in bone marrow transplant recipients: report of two cases and review. Clin Infect Dis. 1999;29(2):429-433.

18. Oksenhendler E, Cadranel J, Sarfati C, et al. Toxoplasma gondii pneumonia in patients with the acquired immunodeficiency syndrome. Am J Med. $1990 ; 88(5 \mathrm{~N}): 18 \mathrm{~N}-21 \mathrm{~N}$.

19. Leal FE, Cavazzana CL, de Andrade HF Jr, Galisteo A Jr, de Mendonça JS, Kallas EG. Toxoplasma gondii pneumonia in immunocompetent subjects: case report and review. Clin Infect Dis. 2007;44(6):e62-e66.

20. Vijayan VK. Parasitic lung infections. Curr Opin Pulm Med. 2009;15(3): 274-282. 


\section{Publish your work in this journal}

The International Medical Case Reports Journal is an international, peer-reviewed open-access journal publishing original case reports from all medical specialties. Previously unpublished medical posters are also accepted relating to any area of clinical or preclinical science. Submissions should not normally exceed 2,000 words or

4 published pages including figures, diagrams and references. The manuscript management system is completely online and includes a very quick and fair peer-review system, which is all easy to use. Visit http://www.dovepress.com/testimonials.php to read real quotes from published authors.

Submit your manuscript here: http://www.dovepress.com/international-medical-case-reports-journal-journal 